\title{
The Inflammatory Cytokine Profile of Patients with Malignant Pleural Effusion Treated with Pleurodesis
}

\author{
Li-Han Hsu 1,2,3@ , Thomas C. Soong ${ }^{4}$, Nei-Min Chu ${ }^{5}$, Chung-Yu Huang 1,6® , \\ Shu-Huei Kao $1,6, * \mathbb{D}$ and Yung-Feng Lin $1,6, * \mathbb{D}$ \\ 1 Ph.D. Program in Medical Biotechnology, College of Medical Science and Technology, \\ Taipei Medical University, Taipei 11031, Taiwan; lhhsu@kfsyscc.org (L.-H.H.); \\ d609105006@tmu.edu.tw (C.-Y.H.) \\ 2 Division of Pulmonary and Critical Care Medicine, Sun Yat-Sen Cancer Center, Taipei 11259, Taiwan \\ 3 Department of Medicine, School of Medicine, National Yang-Ming University, Taipei 11221, Taiwan \\ Department of Radiology, Sun Yat-Sen Cancer Center, Taipei 11259, Taiwan; clsoong@kfsyscc.org \\ 5 Department of Medical Oncology, Sun Yat-Sen Cancer Center, Taipei 11259, Taiwan; nmchu@kfsyscc.org \\ 6 School of Medical Laboratory Science and Biotechnology, College of Medical Science and Technology, \\ Taipei Medical University, Taipei 11031, Taiwan \\ * Correspondence: kaosh@tmu.edu.tw (S.-H.K.); yflin@tmu.edu.tw (Y.-F.L.)
}

Received: 10 November 2020; Accepted: 9 December 2020; Published: 11 December 2020

\begin{abstract}
Patients with malignant pleural effusion (MPE) who underwent successful pleurodesis survive longer than those for whom it fails. We hypothesize that the therapy-induced inflammatory responses inhibit the cancer progression, and thereby lead to a longer survival. Thirty-three consecutive patients with MPE that were eligible for bleomycin pleurodesis between September 2015 and December 2017 were recruited prospectively. Nineteen patients (57.6\%) achieved fully or partially successful pleurodesis, while 14 patients either failed or survived less than 30 days after pleurodesis. Two patients without successful pleurodesis were excluded because of missing data. Interleukin (IL)-1 beta, IL-6, IL-10, transforming growth factor beta, tumor necrosis factor alpha (TNF- $\alpha$ ), and vascular endothelial growth factor in the pleural fluid were measured before, and after 3 and $24 \mathrm{~h}$ of pleurodesis. Their pleurodesis outcome and survival were monitored and analyzed. Patients who underwent successful pleurodesis had a longer survival rate. Patients without successful pleurodesis had significantly higher TNF- $\alpha$ and IL-10 levels in their pleural fluid than in the successful patients before pleurodesis. Following pleurodesis, there was a significant increment of IL-10 in the first three hours in the successful patients. In contrast, significant increments of TNF- $\alpha$ and IL-10 were found in the unsuccessful patients between 3 and $24 \mathrm{~h}$ after pleurodesis. The ability to produce specific cytokines in the pleural space following pleurodesis may be decisive for the patient's outcome and survival. Serial measurement of cytokines can help allocate the patients to adequate treatment strategies. Further study of the underlying mechanism may shed light on cytokine therapies as novel approaches.
\end{abstract}

Keywords: cytokine; inflammation; malignant pleural effusion; pleurodesis; survival

\section{Introduction}

Pleurodesis is regarded as a symptomatic treatment to prevent fluid re-accumulation in patients with malignant pleural effusion (MPE) [1,2]. Talc pleurodesis had been demonstrated as having a favorable impact on the survival of patients with MPE [3,4]. Tremblay et al. showed that patients who spontaneously pleurodesed after indwelling pleural catheter placement survived longer [5]. Ren et al. reported that the intrapleural staphylococcal superantigen has a survival benefit in addition to the resolution of MPE in patients with non-small cell lung cancer [6]. Recently, we showed that patients 
who underwent successful minocycline pleurodesis had a longer cancer-specific survival than those for whom it failed $[7,8]$. The successfully induced inflammatory response is proposed to prohibit the tumor invasion and metastasis, rather than simply through the physical barrier by the fibrin formation [8].

There are continued improvements to our understanding of the molecular connections between the inflammation and cancer $[9,10]$. While chronic inflammation might promote tumor formation, acute inflammation may well hamper the process, and is indeed used therapeutically to inhibit the tumor $[10,11]$. Cytokines are signaling molecules that are key mediators of inflammation. They can be generally classified as pro-inflammatory or anti-inflammatory, and as tumorigenic or tumor suppressive [12]. Interleukin-1 beta (IL-1 $\beta$ ), IL-6, IL-10, transforming growth factor beta (TGF- $\beta$ ), and tumor necrosis factor alpha (TNF- $\alpha$ ) are representative cytokines that are important modulators of inflammation and cancer progression $[9,10]$. Interleukin- 6 and TNF- $\alpha$ are usually reported as pro-inflammatory cytokines. Interleukin-10 is a cytokine with anti-inflammatory properties. Interleukin- 1 beta and TGF- $\beta$ have dual function and pleiotropic nature. Vascular endothelial growth factor (VEGF) is a potent stimulator of angiogenesis and the mediator of the pleural fluid formation [13].

In the study, serial measurements of IL- $1 \beta$, IL-6, IL-10, TGF- $\beta$, TNF- $\alpha$, and VEGF in pleural fluid before and after chemical pleurodesis were performed prospectively in patients with MPE. They were correlated with the pleurodesis outcome and survival. We tried to find the differences in the cytokine profile between patients that succeeded in pleurodesis and those that did not succeed, and identify the cytokine decisive for the prognosis.

\section{Material and Methods}

\subsection{Patients and Pleurodesis}

Consecutive patients with symptomatic MPE that were eligible for chemical pleurodesis at the Sun-Yat Sen Cancer Center, a 200-bed hospital, were prospectively recruited between September 2015 and December 2017. To reduce the confounding factors, patients underwent intrapleural urokinase therapy for loculated MPE or a trapped lung before pleurodesis was excluded $[8,14]$. Loculated MPE was defined as fluid collections with septa seen on chest computed tomography and/or ultrasonography or air-fluid levels in the pleural space on the chest radiograph. A trapped lung was suggested by mechanical restriction of the visceral pleura preventing lung expansion. All the patients received treatment for the underlying primary tumors according to the current guidelines and were followed by the medical oncologists. All the recruited subjects signed an informed consent for the procedures and the laboratory study. The institutional review board of the Sun Yat-Sen Cancer Center approved this study (No. 20160223A and No. 20170220A). The study was also approved by the ethics committee of the Sun Yat-Sen Cancer Center, and it was conducted in accordance with the ethical principles stated in the Declaration of Helsinki or the guidelines on good clinical practice.

Since the discontinuation of the commercial production of minocycline in Taiwan during the study period, bleomycin has been adopted as the sclerosing agent [15]. In contrast to the talc poudrage, which cannot be blown through a catheter, and slurry accumulation in the dependent areas, bleomycin allows for a more even distribution in the pleural space. A size eight to $14 \mathrm{Fr}$ self-retaining intrapleural catheter (SKATERTM Single step drainage set; Argon Medical Devices, Athens, TX, USA) was inserted. Pleurodesis was indicated on near-complete ipsilateral lung re-expansion when the daily drainage decreased to less than $150 \mathrm{~mL}$ for two consecutive days. Eligible patients were infused with $60 \mathrm{IU}$ bleomycin (Nippon Kayaku Co. Ltd., Tokyo, Japan) diluted in 100mL sterile saline via the intrapleural catheter. The catheter was clamped for three hours after the instillation of bleomycin, and then reopened for suction. Patients were encouraged to change positions during the treatment to facilitate the mixing of the bleomycin with the pleural fluid.

The LENT prognostic score, concerning the lactate dehydrogenase level in the pleural fluid, the Eastern Cooperative Oncology Group performance score, serum neutrophil-to-lymphocyte ratio, and the tumor type were evaluated for each patient [16]. The driver oncogene status of the lung 
adenocarcinoma, such as the epidermal growth factor receptor (EGFR) mutations, the echinoderm microtubule-associated protein like 4-anaplastic lymphoma kinase (EML4-ALK) translocation, and the estrogen receptor/progesterone receptor/human EGFR 2 status of breast cancer were recorded.

\subsection{Pleural Fluid Sample Collection}

In concordance with the daily practice, a pleural fluid sample was obtained through the intrapleural catheter immediately before the pleurodesis, three hours at the reopening of the catheter, and $24 \mathrm{~h}$ later, prior to the removal of the catheter. The pleural fluid sample (up to $15 \mathrm{~mL}$ ) was immediately centrifuged at $10,000 \times g$ for $10 \mathrm{~min}$ to remove the cell debris and aggregates, and then stored at $-80^{\circ} \mathrm{C}$ until measurement.

\subsection{Measurement of Pleural Fluid Inflammatory Cytokines and VEGF}

The levels of IL-1 $\beta$, IL-6, IL-10, TGF- $\beta$, TNF- $\alpha$ and VEGF in the supernatants were measured by Bio-Plex ${ }^{\circledR}$ Pro Human Cytokine Multiplex assays (Bio-Rad Laboratories, Hercules, CA, USA) with MagPlex beads in a flat bottom microtiter plate according to the manufacturer's instructions. Antibody-coupled capture beads were prepared and plated. The plate was again incubated on a shaker and streptavidin-phycoerythin solution was added to the wells. After a last incubation step, beads were resuspended in assay buffer and the absorbance was measured with a MagPix (Luminex Corporation) using the xPONENT software (Luminex Corporation, Austin, TX, USA).

\subsection{Assessment of the Pleurodesis Outcomes and Analysis of the Survival}

Follow-up chest radiographs were obtained at one, three, and six months after pleurodesis and repeated as and when required. The success or failure of pleurodesis was determined according to the relevant definitions proposed by the American Thoracic Society and the European Respiratory Society Consensus Statement [1]. Complete success was defined as the long-term relief of symptoms related to the effusion, with the absence of the fluid re-accumulation on the chest radiograph until death. Partial success was defined as the diminution of the dyspnea related to the effusion, with only partial re-accumulation of fluid (less than $50 \%$ of the initial level), with no further therapeutic thoracenteses required for the remainder of the patient's life. Lack of success, as previously mentioned, was determined as failed pleurodesis.

Fair-to-moderate inter-observer agreements about the definition of the non-expandable lung have been reported [17]. Independent interpretation of the pleurodesis outcome by two assessors (T.C.S. and L.-H.H.), followed by the consensus judgement, was completed in the study to reduce the observer bias.

The survival time was calculated from the date of diagnosis of MPE and censored at the date of death or the last follow-up. The overall survival rate was compared between the patients that had succeeded and failed the pleurodesis.

The baseline values and changes in IL-1 $\beta$, IL- 6 , IL-10, TGF- $\beta$, TNF- $\alpha$, and VEGF levels in the pleural fluids were compared between the patients with successful pleurodesis and those without. Because the pleural fluid concentrations of IL- $1 \beta$, IL-6, IL-10, TGF- $\beta$, TNF- $\alpha$, and VEGF were highly variable in patients with MPE [18], we also used the fold change within the individual patients as a comparison [19]. In addition to comparison between groups, comparison was also made at different time points within each group. Linear regression analyses were performed to measure the correlations between different cytokines before and $24 \mathrm{~h}$ after pleurodesis, and were presented with Pearson's correlation coefficient with the significance level.

\subsection{Statistical Analysis}

Descriptive statistics of mean, median, standard deviation, and frequency were used to process the demographic and laboratory data. Continuous variables were compared using the one-way ANOVA on ranks with SigmaPlot 14.0 (Systat Software, Inc.; San Jose, CA, USA), whereas categorical 
variables were compared using the chi-square test or Fisher's exact test. A $p$ value of less than 0.05 for comparisons was considered to represent statistical significance. Survival estimates were derived by the Kaplan-Meier plots, while log-rank tests were used to assess the differences in survival among the groups using the statistical software package SAS, version 9.4 (SAS Institute; Cary, NC, USA).

\section{Results}

\subsection{Patients' Characteristics and Pleurodesis Outcomes}

There were 84 patients diagnosed with MPE in the study period. Thirty-three patients underwent simple bleomycin pleurodesis, and 19 patients (57.6\%) achieved successful or partially successful pleurodesis (10 with breast cancer and nine with lung adenocarcinoma). Nine patients failed the pleurodesis (three with lung adenocarcinoma, three with breast cancer, one with small cell lung cancer, one with ovarian cancer, and one with bladder urothelial carcinoma), with pleural fluid re-accumulation before death. Five patients survived less than 30 days after pleurodesis, with a shorter follow-up to evaluate the pleurodesis outcome (two with breast cancer, one with small cell lung cancer, one with ovarian cancer, and one with gastric cancer). The age, gender, and smoking history appeared comparable among the patients who succeeded or failed pleurodesis or survived less than 30 days (Table 1). Patients who underwent successful pleurodesis, failed the pleurodesis, and survived less than 30 days had a mean value of LENT score, $2.84,3.67$, and 4.40 , respectively $(p=0.020)$.

\subsection{Survival Differences}

On the follow-up, patients who underwent successful pleurodesis had a significantly longer overall survival than those for whom it failed (median, 367 vs. 81 days; $p<0.001$ ) (Figure 1).

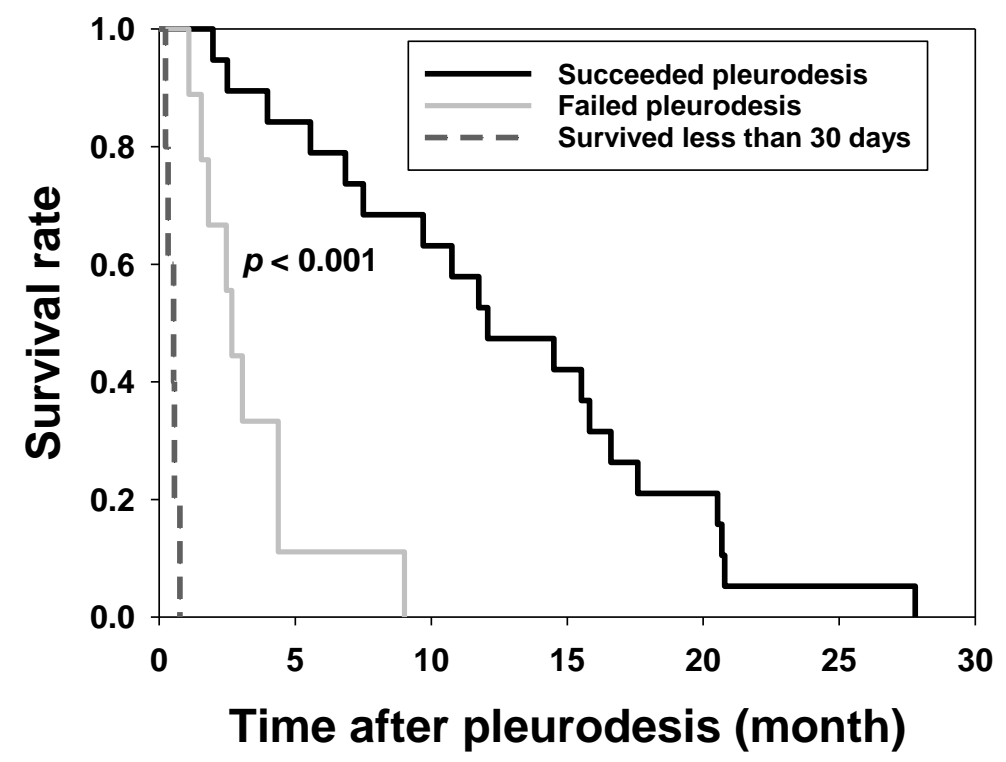

Figure 1. Survival after pleurodesis. The survival rates of patients who underwent successful pleurodesis (black line), patients for whom pleurodesis failed (grey line), and patients who survived less than 30 days (dotted line) were plotted against the time after pleurodesis.

\subsection{Pleural Fluid Inflammatory Cytokines and VEGF between Groups}

Two patients with breast cancer had dry drainage at the $24 \mathrm{~h}$ collection that led to missing data at the time point and were excluded from the subsequent analysis—one had failed pleurodesis and the other survived less than 30 days. We combined the remaining patients with failed pleurodesis and the patients who survived less than 30 days as a group $(n=12)$ in the subsequent cytokine analysis, so as 
to compare them with the successful pleurodesis group $(n=19)$, considering the obvious prognostic difference and aim to investigate the survival benefit of the patients who succeeded pleurodesis.

For the baseline level, patients without successful pleurodesis had a significantly higher pleural fluid TNF- $\alpha$ and IL-10 level before pleurodesis than those who succeeded (Table 2 T1 values and Figure 2). Following the instillation of bleomycin, there was a significant increment of IL-10 in the first three hours in patients who underwent successful pleurodesis. By contrast, there was a significant increment of TNF- $\alpha$, and IL-10 between 3 and $24 \mathrm{~h}$ in patients without successful pleurodesis (Table 3 , and Figure 3).

Table 1. Characteristics of the patients underwent pleurodesis stratified by the results.

\begin{tabular}{|c|c|c|c|c|}
\hline Variable & $\begin{array}{c}\text { Patients } \\
\text { Succeeded } \\
\text { Pleurodesis } \\
(n=19)\end{array}$ & $\begin{array}{l}\text { Patients Failed } \\
\text { Pleurodesis } \\
(n=9)\end{array}$ & $\begin{array}{l}\text { Patients Survived } \\
\text { Less than } 30 \text { Days } \\
\qquad(n=5)\end{array}$ & $p$ Value \\
\hline Mean age, years & $55.9(38.6-74.5)$ & $60.4(51.2-70.8)$ & $60.6(48.6-70.1)$ & 0.392 \\
\hline Gender & & & & 0.142 \\
\hline Female & 16 & 4 & 4 & \\
\hline Male & 3 & 5 & 1 & \\
\hline Smoking history & & & & 0.165 \\
\hline Yes & 4 & 5 & 1 & \\
\hline No & 15 & 4 & 4 & \\
\hline Pleural fluid LDH level (IU/L) & & & & $<0.001$ \\
\hline$<1500$ & 19 & 7 & 4 & \\
\hline$>1500$ & 0 & 2 & 1 & \\
\hline ECOG PS & & & & 0.014 \\
\hline 0 & 1 & 1 & 0 & \\
\hline 1 & 14 & 3 & 0 & \\
\hline 2 & 4 & 5 & 5 & \\
\hline Serum NLR & & & & 0.042 \\
\hline$<9$ & 15 & 5 & 1 & \\
\hline$>9$ & 4 & 4 & 4 & \\
\hline Tumor type & & & & 0.859 \\
\hline Lung adenocarcinoma & 9 & 3 & 0 & \\
\hline sensitive EGFR (+) & 6 & 0 & 0 & \\
\hline sensitive EGFR (-) & 3 & 3 & 0 & \\
\hline breast cancer & 10 & 3 & 2 & \\
\hline ER or PR or HER2/neu (+) & 9 & 3 & 1 & \\
\hline TNBC & 1 & 0 & 1 & \\
\hline ovarian cancer & 0 & 1 & 1 & \\
\hline small cell lung cancer & 0 & 1 & 1 & \\
\hline bladder urothelial carcinoma & 0 & 1 & 0 & \\
\hline gastric cancer & 0 & 0 & 1 & \\
\hline Total LENT score & & & & 0.020 \\
\hline low risk $(0-1)$ & $0(0 \%)$ & $1(11.1 \%)$ & $0(0 \%)$ & \\
\hline moderate risk (2-4) & $19(100 \%)$ & $5(55.6 \%)$ & $3(60 \%)$ & \\
\hline high risk (5-7) & $0(0 \%)$ & $3(33.3 \%)$ & $2(40 \%)$ & \\
\hline mean & 2.84 & 3.67 & 4.40 & \\
\hline
\end{tabular}

ECOG PS, Eastern Cooperative Oncology Group performance status; EGFR, epidermal growth factor receptor; ER, estrogen receptor; HER2, human EGFR 2; LDH, lactate dehydrogenase; NLR, neutrophil-to-lymphocyte ratio; PR, progesterone receptor; TNBC, triple-negative breast cancer. The LENT score is a validated risk stratification system to predict survival in malignant pleural effusion, calculated on the basis of pleural fluid LDH, ECOG PS, serum NLR and tumor type. 
Table 2. Measured pleural fluid cytokine and VEGF levels before pleurodesis (T1), 3 hours after pleurodesis (T2), and 24 hours later before the removal of the intrapleural catheter (T3) were compared between patients who underwent successful pleurodesis $(n=19)$ and those that did not $(n=12)$.

\begin{tabular}{|c|c|c|c|c|c|c|}
\hline & IL-1 $\beta(\mathrm{pg} / \mathrm{mL})$ & IL-6 (pg/mL) & IL-10 (pg/mL) & TGF- $\beta(\mathrm{pg} / \mathrm{mL})$ & TNF- $\alpha(\mathrm{pg} / \mathrm{mL})$ & VEGF $(\mathrm{pg} / \mathrm{mL})$ \\
\hline T1 & $p=0.745$ & $p=0.465$ & $p=0.047$ & $p=0.105$ & $p=0.006$ & $p=0.626$ \\
\hline Succeeded & $0.34(0.01 \sim 58.26)$ & $3351(14.92 \sim 29,484)$ & $10.94(0.48 \sim 63.85)$ & $553.9(39.00 \sim 21,979)$ & $3.19(0.23 \sim 45.85)$ & $179(2.2 \sim 6707)$ \\
\hline Not succeeded & $1.405(0.01 \sim 3769)$ & $272.8(30.9 \sim 25,967)$ & $18.06(8.31 \sim 116.4)$ & $10,016(42.16 \sim 38,261)$ & $9.58(3.19 \sim 355.7)$ & $486.7(2.2 \sim 1702)$ \\
\hline $\mathrm{T} 2$ & $p=0.715$ & $p=0.256$ & $p=0.612$ & $p=0.598$ & $p=0.068$ & $p=0.871$ \\
\hline Succeeded & $1.75(0.01 \sim 94.33)$ & $3414(42.99 \sim 27,600)$ & $11.12(0.61 \sim 104.6)$ & $174.4(42.16 \sim 6536)$ & $7.83(0.59 \sim 531.2)$ & $231(9.9 \sim 6255)$ \\
\hline Not succeeded & $2.925(0.01 \sim 114.6)$ & $250.5(29.05 \sim 27,626)$ & $10.86(3.62 \sim 66.38)$ & $174.4(16.9 \sim 32,192)$ & $11.66(2.44 \sim 214.7)$ & $234.3(2.2 \sim 5724)$ \\
\hline T3 & $p=0.372$ & $p=0.516$ & $p=0.209$ & $p=0.273$ & $p<0.001$ & $p=0.626$ \\
\hline Succeeded & $2.6(0.005 \sim 33.84)$ & $4041(72.48 \sim 30,480)$ & $17(1.58 \sim 250.5)$ & $969.1(100.5 \sim 16,598)$ & $4.15(0.23 \sim 210.5)$ & $393.5(2.2 \sim 5935)$ \\
\hline Not succeeded & $1.715(0.1 \sim 3953)$ & $773.8(171.4 \sim 29,300)$ & 43.87 (9.76 251.1) & $1730(35.84 \sim 25,019)$ & 46.53 (14.48 294.3) & $678.2(2.2 \sim 5042)$ \\
\hline
\end{tabular}

Data expressed as median and range. IL, interleukin; TGF- $\beta$, transforming growth factor beta; TNF- $\alpha$, tumor necrosis factor alpha; VEGF, vascular endothelial growth factor. 

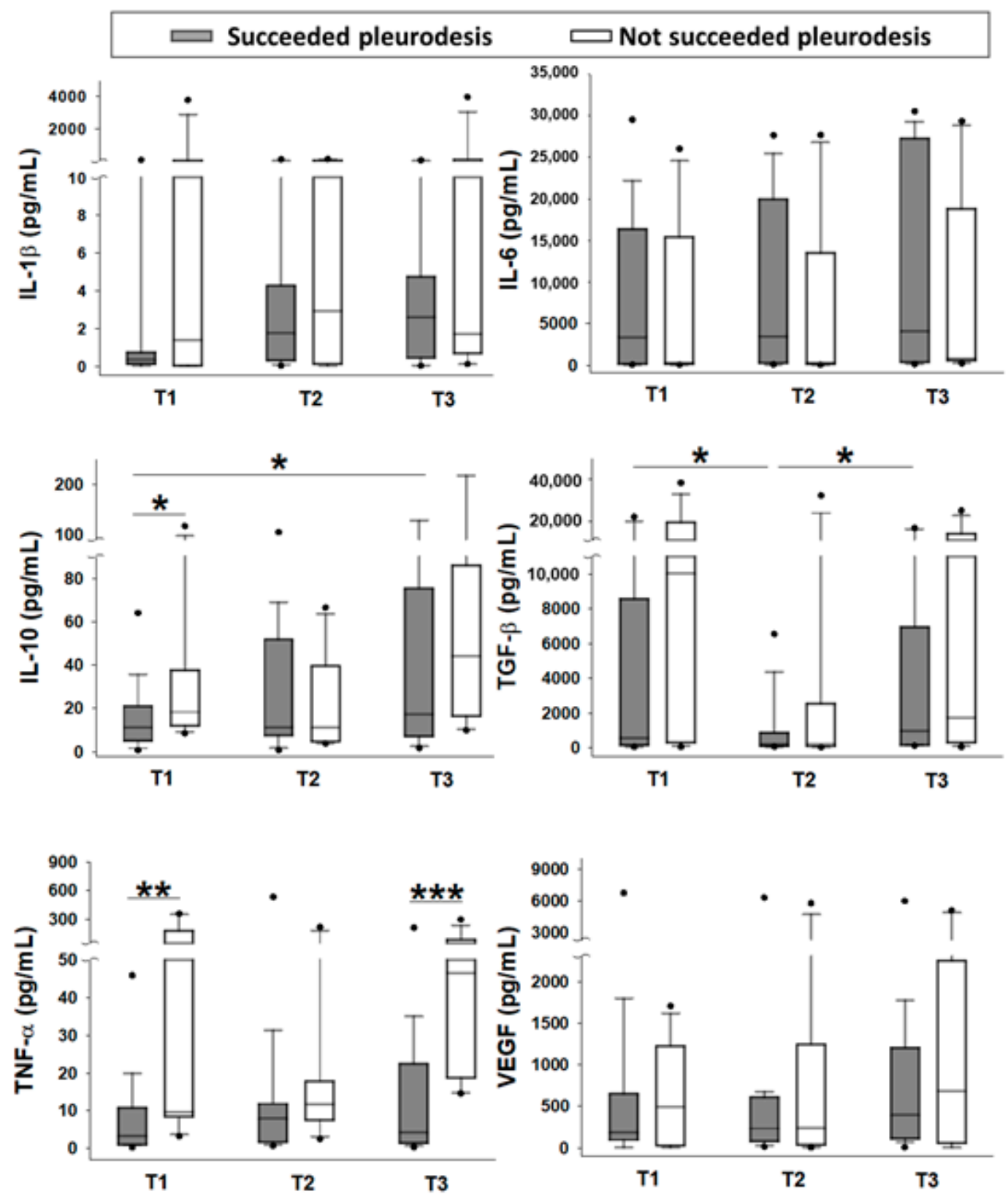

Figure 2. Measured cytokines in the pleural fluid at different time points. Interleukin (IL)-1 $\beta$, IL-6, IL-10, transforming growth factor beta (TGF- $\beta$ ), tumor necrosis factor alpha (TNF- $\alpha$ ), and vascular endothelial growth factor (VEGF) levels were compared between patients who succeeded pleurodesis (grey column; $n=19$ ) and those not succeeded (white column; $n=12$ ). Comparison was also made at different time points within each group. Box plots demonstrate the concentrations in the pleural fluid. The dots represent the 5th and 95th percentiles, respectively. The error bars cover the 10th to 90th percentiles and the box covers 25 th to 75 th percentiles. The line within the box represents the median value. T1, before pleurodesis; T2, three hours after pleurodesis; T3, $24 \mathrm{~h}$ after pleurodesis; ${ }^{*} p<0.05$; ** $p<0.01 ;{ }^{* * *} p<0.001$ 
Table 3. Fold changes of pleural fluid cytokines and VEGF levels between different time points were compared between patients who succeeded pleurodesis $(n=19)$ and those not succeeded $(n=12)$.

\begin{tabular}{|c|c|c|c|c|c|c|}
\hline & IL-1 $\beta$ & IL-6 & IL-10 & TGF- $\beta$ & TNF- $\alpha$ & VEGF \\
\hline $\mathrm{T} 2 / \mathrm{T} 1$ & $p=0.068$ & $p=0.516$ & $p=0.008$ & $p=0.105$ & $p=0.273$ & $p=0.776$ \\
\hline Succeeded & $3.481(0.073 \sim 145.1)$ & $0.95(0.159 \sim 6.986)$ & $1.579(0.313 \sim 8.398)$ & $0.884(0.003 \sim 44.37)$ & $1.272(0.298 \sim 11.59)$ & $0.96(0.106 \sim 44.65)$ \\
\hline Not succeeded & $1.040(0.030 \sim 11.8)$ & $0.916(0.323 \sim 5.291)$ & $0.511(0.112 \sim 3.68)$ & $0.287(0.001 \sim 64.36)$ & $0.96(0.007 \sim 12.46)$ & $1.002(0.092 \sim 13.85)$ \\
\hline T3/T2 & $p=0.081$ & $p=0.394$ & $p=0.019$ & $p=0.715$ & $p=0.019$ & $p=0.57$ \\
\hline Succeeded & $0.964(0.009 \sim 38.17)$ & $1.708(0.203 \sim 21.29)$ & $1.718(0.14 \sim 22.52)$ & 1.937 (0.195 289.6) & $1(0.099 \sim 10.63)$ & $1.585(0.087 \sim 9.531)$ \\
\hline Not succeeded & $7.106(0.463 \sim 85)$ & $2.276(0.978 \sim 12.95)$ & $2.831(0.963 \sim 8.818)$ & $3.045(0.013 \sim 345.4)$ & $2.704(0.403 \sim 38.05)$ & $1.244(0.131 \sim 16.62)$ \\
\hline $\mathrm{T} 3 / \mathrm{T} 1$ & $p=0.855$ & $p=0.598$ & $p=0.273$ & $p=0.109$ & $p=0.685$ & $p=0.903$ \\
\hline Succeeded & $4.135(0.039 \sim 88.63)$ & $1.548(0.182 \sim 16.9)$ & $2.576(0.241 \sim 10.96)$ & 0.887 (0.060 128.9) & $1.922(0.072 \sim 10.61)$ & $1.452(0.021 \sim 104.4)$ \\
\hline Not succeeded & $5.75(0.812 \sim 85)$ & $1.941(0.816 \sim 21.71)$ & $1.361(0.883 \sim 7.808)$ & $0.768(0.087 \sim 1.614)$ & $2.072(0.261 \sim 9.734)$ & $1.153(0.282 \sim 19.19)$ \\
\hline
\end{tabular}

Data expressed as median and range. 

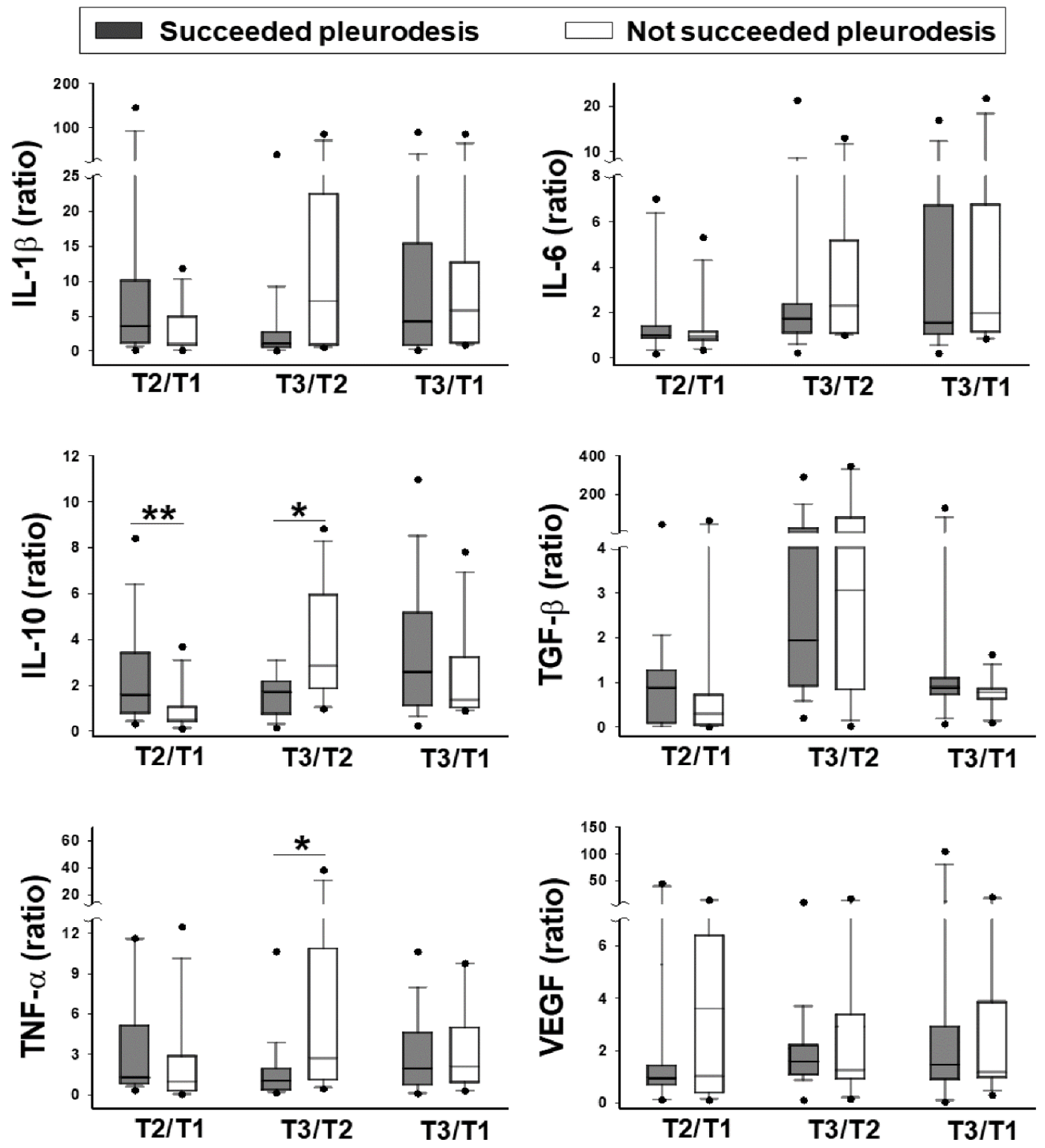

Figure 3. Fold change of the cytokines in the pleural fluid. IL-1 $\beta$, IL-6, IL-10, TGF- $\beta$, TNF- $\alpha$, and VEGF levels measured at the later time points were divided by those measured at the earlier time points and compared between patients who underwent successful pleurodesis (grey column; $n=19$ ) and those not succeeded (white column; $n=12$ ). Box plots demonstrated the ratios. The dots represent the 5th and 95th percentiles, respectively. The error bars cover the 10th to 90th percentiles and the box covers the 25th to 75 th percentiles. The line within the box represents the median value. T1, before pleurodesis; $\mathrm{T} 2$, three hours after pleurodesis; T3, $24 \mathrm{~h}$ after pleurodesis; ${ }^{*} p<0.05 ;{ }^{* *} p<0.01$.

There was no significant difference in the baseline levels or changes following the pleurodesis of IL-1 $\beta$, IL-6, TGF- $\beta$, and VEGF between the patients who underwent successful pleurodesis and those that did not (Tables 2 and 3; Figures 2 and 3).

\subsection{Comparison of Pleural Fluid Inflammatory Cytokines and VEGF at Different Time Points within Each Groups}

Compared with the relatively lower baseline level, there was a significant increase in IL-10 at $24 \mathrm{~h}$ in patients who underwent successful pleurodesis (Figure 2). An initial suppression of TGF- $\beta$, followed by a subsequent elevation was noted in both groups, with significant differences in patients who underwent successful pleurodesis. 


\subsection{Correlations between Different Inflammatory Cytokines}

Pleural fluid IL-1 $\beta$ and TNF- $\alpha$ was positively correlated before $(r=0.726, p<0.001)$ and at $24 \mathrm{~h}$ after pleurodesis $(r=0.771, p<0.001)$. Pleural fluid IL-6 and TGF- $\beta$ was negatively correlated before $(r=-0.550, p=0.001)$ and at $24 \mathrm{~h}$ after pleurodesis $(r=-0.608, p<0.001)$.

\section{Discussion}

To the best of our knowledge, this is the first study to measure the inflammatory cytokines and VEGF changes following pleurodesis and correlate these factors with the outcome and survival. The possible confounders were taken into consideration (Table 1). The pleural fluid TNF- $\alpha$ levels were significantly higher in the malignant pleural effusion, which may be attributed to the increased local production in the pleural cavity by macrophage, T-lymphocyte, or mesothelial cells upon exposure to inflammatory process [20]. Patients without successful pleurodesis had a higher pleural fluid TNF- $\alpha$ level before pleurodesis. Following pleurodesis, they had an increment of TNF- $\alpha$ in the late stage (between three and $24 \mathrm{~h}$ ). The tumor necrosis factor alpha is usually regarded as pro-inflammatory and tumorigenic. Deregulation of the TNF- $\alpha$ signaling pathway is associated with many inflammatory disorders, including rheumatoid arthritis, and inflammatory bowel disease, as the monoclonal antibody to TNF- $\alpha$ has been a standard treatment for these diseases. TNF- $\alpha$ have divergent effects on the regulatory $\mathrm{T}$ cells, and this contributes to their development and accumulation, although it can downregulate their suppressive capacity in some instances [21,22].

Patients with successful pleurodesis had a significant increment of IL-10 in the first three hours following the instillation of bleomycin. The early surge of IL-10 following pleurodesis accompanied by a longer survival suggests an anti-tumor effect of IL-10. On the contrary, the higher pleural fluid IL-10 levels before pleurodesis and a late increment of IL-10 between 3 and $24 \mathrm{~h}$ following pleurodesis in patients without successful pleurodesis suggested the crucial role of IL-10 as a feedback regulator of the increased pro-inflammatory cytokine, TNF- $\alpha[12,23,24]$. In fact, we also observed feedback regulation in patients who underwent successful pleurodesis when performing intragroup comparison (Figure 2). IL-10 is usually regarded as an anti-inflammatory cytokine and has been reported to exert anti-tumor effects through the increasing tumor antigen-specific CD8+ T cell infiltration and the INF- $\gamma$-mediated induction of antigen presentation [12,25-27]. Pegylated IL-10 had been developed and demonstrated as an effective anti-tumor immune response with long-lasting immunologic memory [28]. Clinical efficacy has been seen as monotherapy, or in a combination with anti-PD-1 antibodies [29]. However, IL-10 has paradoxical effects on different types of immune response and is considered a potential switcher of immunity [26,27].

The indiscrimination in the baseline levels or changes following pleurodesis of IL-1- $\beta$, IL-6, and TGF- $\beta$ between patients with or without successful pleurodesis was consistent with their reported dual tumor promoting or inhibitory function. Interleukin-6 is regarded as a pro-inflammatory cytokine, although certain anti-inflammatory activities were also attributed to IL-6 [30,31]. The IL-6/JAK (Janus tyrosine kinase)/STAT (signal transducers and activators of transcription) signaling pathway is aberrantly hyperactivated in many types of cancer. Interleukine- 6 also exerts immunosuppression in the tumor environment by stimulating the infiltration of myeloid-derived suppressor cells, tumor-associated neutrophils, and cancer stem-like cells. Interleukin-1 $\beta$ activates innate immune cells including antigen presenting cells, and drives polarization of CD4+ T cells towards T helper type (Th) 1 and Th17 cells, to exert anti-tumor effects [32]. Activation of the NLRP3 inflammasome in dendritic cells induces IL-1 $\beta$-dependent adaptive immunity against tumors [33]. Contrarily, IL-1 $\beta$ within the tumor microenvironment has been reported to promote carcinogenesis, tumor growth, and metastasis through driving chronic non-resolved inflammation, endothelial cell activation, tumor angiogenesis, and the induction of immune-suppressive cells. During intragroup comparison, both groups had an initial suppression of TGF- $\beta$, followed by a subsequent elevation, especially in patients who underwent successful pleurodesis (Figure 2). In the early stages of cancer, TGF- $\beta$ functions as a tumor suppressor, while in the later stages, the TGF- $\beta$ exerts tumor-promoting effects [34-36]. Its effects also depend 
on the cellular context. TGF- $\beta$ from the inflammatory tumor microenvironment may cause cancer cell apoptosis and tumor suppression. In contrast, it may also induce an epithelial-mesenchymal transition that promotes cancer cell invasion and metastasis, cancer stem cell heterogeneity and drug resistance $[34,35]$. TGF- $\beta$ had been adopted as a sclerosing agent for pleurodesis $[37,38]$, and the anti-TGF- $\beta$ antibody could inhibit the pleural fibrosis in the rabbit empyema model [39]. Contrarily, the TGF- $\beta$ inhibitor was proposed as a new line of defense against cancers. Pleural fluid IL- $1 \beta$ and TNF- $\alpha$ were positively correlated, and pleural fluid IL- 6 and TGF- $\beta$ were negatively correlated, both before and $24 \mathrm{~h}$ after pleurodesis. The pleiotropic nature of IL- $1 \beta$ or TGF- $\beta$ makes it a challenging target requiring further study [36].

Similar to the study of Hooper et al. [40], and our earlier study [7], no association existed between the baseline pleural fluid VEGF levels and pleurodesis failure. There was also no association between the changes in pleural fluid VEGF following pleurodesis with the outcome.

The mesothelium itself may regulate the first steps of the pleural fibrosis following the instillation of a sclerosing agent, through the inflammatory response, which is decisive for the pleurodesis outcome and survival [41,42]. Further studies to observe the release of inflammatory cytokines from the mesothelial cells or other cells within the pleural space, such as macrophages after the addition of the sclerosing agent, and the effects of the conditional media, cytokines and their antagonists on cancer cell viability, apoptosis, pyroptosis, proliferation, migration, and invasion are warranted to clarify the mechanism [43-45].

The choice of MPE managements, i.e., chemical pleurodesis, indwelling pleural catheter drainage or repeat thoracenteses, depends on the expected survival, lung expandability, and cost-effectiveness, which remains a challenge for clinicians [1,2]. The LENT scoring system appeared to be a valuable prognostic score in patients with MPE [16], as it predicted the shorter survival of patients who failed pleurodesis and may aid clinical decision making in the diverse patient population. The ability to produce specific cytokines in the pleural space after the instillation of the sclerosing agent may be decisive for the pleurodesis outcome and survival. The time points of pleural fluid collection in concordance with the daily practice of pleurodesis in the study allows us to measure the cytokines changes to allocate the patients to adequate treatment strategies in the future. The pleural fluid cytokine concentration $3 \mathrm{~h}$ after pleurodesis might be diluted by the amount of saline instilled with bleomycin. This is a drawback and may need be corrected by the protein concentrations in the pleural fluid.

Manipulation of the co-stimulatory or co-inhibitory checkpoint proteins, such as PD-1 and PD-L1, allows for the reversal of tumor-induced T-cell anergy. Cytokines or their specific inhibitors involved in the signaling between the tumor cells and the microenvironment have not, as yet, been systemically studied. In addition to the immune checkpoint inhibitors, the recombinant cytokines can potentially increase the number of patients who will benefit from the immunotherapy [46]. Strategies to target the tumor immunosuppressive network, rather than targeting a single molecule, should be established in the future. In addition, intrapleural cytokine therapy may have the benefit of focused treatment without a systemic effect for patients with MPE [36].

In this study, more patients with symptomatic MPE underwent chemical pleurodesis (33/84, $39.3 \%)$, as compared with our earlier series (33.2\%) and the historical control (24\%) [8,47]. However, there was still an attrition in the subsequent analysis, such as dry drainage that led to missing data at some time points. The tumor heterogeneity of the study group is another concern. To confirm the study findings, such limitations need to be addressed and could be overcome in the future with more and adequate patients recruited.

\section{Conclusions}

The ability to produce specific cytokines in the pleural space following pleurodesis may be decisive for the patient's outcome and survival. Serial measurement of cytokines can help allocate the patients to adequate treatment strategies. Further study of the underlying mechanism may shed light on cytokine therapies as novel approaches. 
Author Contributions: Conceptualization, L.-H.H., S.-H.K., and Y.-F.L.; Data curation, L.-H.H., S.-H.K., and Y.-F.L.; Formal analysis, L.-H.H., T.C.S., S.-H.K., and Y.-F.L.; Funding acquisition, L.-H.H., S.-H.K., and Y.-F.L.; Investigation, L.-H.H., T.C.S., N.-M.C., C.-Y.H., S.-H.K., and Y.-F.L.; Methodology, L.-H.H., S.-H.K., and Y.-F.L.; Project administration, S.-H.K., and Y.-F.L.; Resources, S.-H.K., and Y.-F.L.; Software, Y.-F.L.; Supervision, S.-H.K., and Y.-F.L.; Validation, L.-H.H., T.C.S., N.-M.C., C.-Y.H., S.-H.K., and Y.-F.L.; Visualization, S.-H.K., and Y.-F.L.; Writing-original draft, L.-H.H., S.-H.K., and Y.-F.L.; Writing-review and editing; L.-H.H., T.C.S., N.-M.C., C.-Y.H., S.-H.K., and Y.-F.L. All authors have read and agreed to the published version of the manuscript.

Funding: This study was funded by the Ministry of Science and Technology, Taiwan (grant no. MOST 106-2314-B-368-001).

Acknowledgments: The authors would like to offer their sincere thanks to Hsiang-Yi Lin, Ming-Chih Chern, and Yung-Yi Cheng for their assistance with the specimen collection; Hsiao-Hsuan Wang for the specimen processing and analysis; Michael Wise for his help with the English language editing; Shiao-Chiu Huang for her assistance with the references preparation.

Conflicts of Interest: The authors declare no conflict of interest. The funders had no role in the design of the study; in the collection, analyses, or interpretation of data; in the writing of the manuscript, or in the decision to publish the results.

\section{References}

1. American Thoracic Society. Management of malignant pleural effusions. Am. J. Respir. Crit. Care Med. 2000, 162, 1987-2001. [CrossRef] [PubMed]

2. Feller-Kopman, D.J.; Reddy, C.B.; DeCamp, M.M.; Diekemper, R.L.; Gould, M.K.; Henry, T.; Iyer, N.P.; Lee, Y.C.G.; Lewis, S.Z.; Maskell, N.A.; et al. Management of malignant pleural effusions. An official ATS/STS/STR clinical practice guideline. Am. J. Respir. Crit. Care Med. 2018, 198, 839-849. [CrossRef] [PubMed]

3. Hirata, T.; Yonemori, K.; Hirakawa, A.; Shimizu, C.; Tamura, K.; Ando, M.; Katsumata, N.; Tanimoto, M.; Fujiwara, Y. Efficacy of pleurodesis for malignant pleural effusions in breast cancer patients. Eur. Respir. J. 2011, 38, 1425-1430. [CrossRef] [PubMed]

4. Korsic, M.; Badovinac, S.; Cucevic, B.; Janevski, Z. Talc pleurodesis improves survival of patients with malignant pleural effusions: Case-control study. Wien. Klin. Wochenschr. 2015, 127, 963-969. [CrossRef]

5. Tremblay, A.; Michaud, G. Single-center experience with 250 tunnelled pleural catheter insertions for malignant pleural effusion. Chest 2006, 129, 362-368. [CrossRef]

6. Ren, S.; Terman, D.S.; Bohach, G.; Silvers, A.; Hansen, C.; Colt, H.; Sahn, S.A. Intrapleural staphylococcal superantigen induces resolution of malignant pleural effusions and a survival benefit in non-small cell lung cancer. Chest 2004, 126, 1529-1539. [CrossRef]

7. Hsu, L.H.; Hsu, P.C.; Liao, T.L.; Feng, A.C.; Chu, N.M.; Kao, S.H. Pleural fluid osteopontin, vascular endothelial growth factor, and urokinase-type plasminogen activator levels as predictors of pleurodesis outcome and prognosticators in patients with malignant pleural effusion: A prospective cohort study. BMC Cancer 2016, 16, 463. [CrossRef]

8. Hsu, L.H.; Feng, A.C.; Soong, T.C.; Ko, J.S.; Chu, N.M.; Lin, Y.F.; Kao, S.H. Clinical outcomes of chemical pleurodesis using a minocycline. Ther. Adv. Respir. Dis. 2019, 13, 1753466619841231. [CrossRef]

9. Schetter, A.J.; Heegaard, N.H.; Harris, C.C. Inflammation and cancer: Interweaving microRNA, free radical, cytokine and p53 pathways. Carcinogenesis 2010, 31, 37-49. [CrossRef]

10. Grivennikov, S.I.; Greten, F.R.; Karin, M. Immunity, inflammation, and cancer. Cell 2010, 140, 883-899. [CrossRef]

11. Sgambato, A.; Cittadini, A. Inflammation and cancer: A multifaceted link. Eur. Rev. Med. Pharmacol. Sci. 2010, 14, 263-268.

12. Opal, S.M.; DePalo, V.A. Anti-inflammatory cytokines. Chest 2000, 117, 1162-1172. [CrossRef] [PubMed]

13. Yano, S.; Shinohara, H.; Herbst, R.S.; Kuniyasu, H.; Bucana, C.D.; Ellis, L.M.; Fidler, I.J. Production of experimental malignant pleural effusions is dependent on invasion of the pleura and expression of vascular endothelial growth factor/vascular permeability factor by human lung cancer cells. Am. J. Pathol. 2000, 157, 1893-1903. [CrossRef]

14. Hsu, L.H.; Soong, T.C.; Feng, A.C.; Liu, M.C. Intrapleural urokinase for the treatment of loculated malignant pleural effusions and trapped lungs in medically inoperable cancer patients. J. Thorac. Oncol. 2006, 1, 460-467. [CrossRef] 
15. Diacon, A.H.; Wyser, C.; Bolliger, C.T.; Tamm, M.; Pless, M.; Perruchoud, A.P.; Solèr, M. Prospective randomized comparison of thoracoscopic talc poudrage under local anesthesia versus bleomycin instillation for pleurodesis in malignant pleural effusions. Am. J. Respir. Crit. Care Med. 2000, 162, 1445-1449. [CrossRef]

16. Clive, A.O.; Kahan, B.C.; Hooper, C.E.; Bhatnagar, R.; Morley, A.J.; Zahan-Evans, N.; Bintcliffe, O.J.; Boshuizen, R.C.; Fysh, E.T.H.; Tobin, C.L.; et al. Predicting survival in malignant pleural effusion: Development and validation of the LENT prognostic score. Thorax 2014, 69, 1098-1104. [CrossRef]

17. Martin, G.A.; Kidd, A.C.; Tsim, S.; Halford, P.; Bibby, A.; Maskell, N.A.; Blyth, K.G. Inter-observer variation in image interpretation and the prognostic importance of non-expansile lung in malignant pleural effusion. Respirology 2020, 25, 298-304. [CrossRef]

18. Chung, C.L.; Chen, C.H.; Sheu, J.R.; Chen, Y.C.; Chang, S.C. Proinflammatory cytokines, transforming growth factor-beta1, and fibrinolytic enzymes in loculated and free-flowing pleural exudates. Chest 2005, 128, 690-697. [CrossRef]

19. Espósito, D.L.A.; Bollela, V.R.; Feitosa, A.L.P.; da Fonseca, B.A.L. Expression profiles of cytokine mRNAs in the pleural fluid reveal differences among tuberculosis, malignancies, and pneumonia-exudative pleural effusions. Lung 2015, 193, 1001-1007. [CrossRef]

20. Odeh, M.; Sabo, E.; Srugo, I.; Oliven, A. Tumour necrosis factor alpha in the diagnostic assessment of pleural effusion. Q. J. Med. 2000, 93, 819-824. [CrossRef]

21. Balkwill, F. Tumor necrosis factor and cancer. Nat. Rev. Cancer 2009, 9, 361-371. [CrossRef]

22. Mehta, A.K.; Gracias, D.T.; Croft, M. TNF activity and T cells. Cytokine 2018, 101, 14-18. [CrossRef]

23. Joyce, D.A.; Gibbons, D.P.; Green, P.; Steer, J.H.; Feldmann, M.; Brennan, F.M. Two inhibitors of pro-inflammatory cytokine release, interleukin-10 and interleukin-4, have contrasting effects on release of soluble p75 tumor necrosis factor receptor by cultured monocytes. Eur. J. Immunol. 1994, 24, 2699-2705. [CrossRef]

24. Dickensheets, H.L.; Freeman, S.L.; Smith, M.F.; Donnelly, R.P. Interleukin-10 upregulates tumor necrosis factor receptor type-II (p75) gene expression in endotoxin-stimulated human monocytes. Blood 1997, 90, 4162-4171. [CrossRef]

25. Mannino, M.H.; Zhu, Z.; Xiao, H.; Bai, Q.; Wakefield, M.R.; Fang, Y. The paradoxical role of IL-10 in immunity and cancer. Cancer Lett. 2015, 367, 103-107. [CrossRef]

26. Geginat, J.; Larghi, P.; Paroni, M.; Nizzoli, G.; Penatti, A.; Pagani, M.; Gagliani, N.; Meroni, P.; Abrignani, S.; Flavell, R.A. The light and the dark sides of Interleukin-10 in immune-mediated diseases and cancer. Cytokine Growth Factor Rev. 2016, 30, 87-93. [CrossRef]

27. Mingomataj, E.Ç.; Bakiri, A.H. Regulator versus effector paradigm: Interleukin-10 as indicator of the switching response. Clin. Rev. Allergy Immunol. 2016, 50, 97-113. [CrossRef]

28. Autio, K.; Oft, M. Pegylated interleukin-10: Clinical development of an immunoregulatory cytokine for use in cancer therapeutics. Curr. Oncol. Rep. 2019, 21, 19. [CrossRef] [PubMed]

29. Naing, A.; Wong, D.J.; Infante, J.R.; Korn, W.M.; Aljumaily, R.; Papadopoulos, K.P.; Autio, K.A.; Pant, S.; Bauer, T.M.; Drakaki, A.; et al. Pegilodecakin combined with pembrolizumab or nivolumab for patients with advanced solid tumours (IVY): A multicentre, multicohort, open-label, phase 1b trial. Lancet Oncol. 2019, 20, 1544-1555. [CrossRef]

30. Johnson, D.E.; O’Keefe, R.A.; Grandis, J.R. Targeting the IL-6/JAK/STAT3 signalling axis in cancer. Nat. Rev. Clin. Oncol. 2018, 15, 234-248. [CrossRef]

31. Kampan, N.C.; Xiang, S.D.; McNally, O.M.; Stephens, A.N.; Quinn, M.A.; Plebanski, M. Immunotherapeutic interleukin-6 or interleukin-6 receptor blockade in cancer: Challenges and opportunities. Curr. Med. Chem. 2018, 25, 4785-4806. [CrossRef]

32. Bent, R.; Moll, L.; Grabbe, S.; Bros, M. Interleukin-1 beta-A friend or foe in malignancies? Int. J. Mol. Sci. 2018, 19, 2155. [CrossRef]

33. Ghiringhelli, F.; Apetoh, L.; Tesniere, A.; Aymeric, L.; Ma, Y.; Ortiz, C.; Vermaelen, K.; Panaretakis, T.; Mignot, G.; Llrich, E.; et al. Activation of the NLRP3 inflammasome in dendritic cells induces IL-1beta-dependent adaptive immunity against tumors. Nat. Med. 2009, 15, 1170-1178. [CrossRef]

34. David, C.J.; Huang, Y.H.; Chen, M.; Su, J.; Zou, Y.; Bardeesy, N.; Lacobuzio-Donahue, C.A.; Massagué, J. TGF- $\beta$ tumor suppression through a lethal EMT. Cell 2016, 164, 1015-1030. [CrossRef] [PubMed] 
35. Fischer, K.R.; Durrans, A.; Lee, S.; Sheng, J.; Li, F.; Wong, S.T.C.; Choi, H.; Rayes, T.E.; Ryu, S.; Troeger, J.; et al. Epithelial-to-mesenchymal transition is not required for lung metastasis but contributes to chemoresistance. Nature 2015, 527, 472-476. [CrossRef]

36. Caja, L.; Dituri, F.; Mancarella, S.; Caballero-Diaz, D.; Moustakas, A.; Giannelli, G.; Fabregat, I. TGF- $\beta$ and the tissue microenvironment: Relevance in fibrosis and cancer. Int. J. Mol. Sci. 2018, 19, 1294. [CrossRef]

37. Light, R.W.; Cheng, D.S.; Lee, Y.C.G.; Rogers, J.; Davidson, J.; Lane, K.B. A single intrapleural injection of transforming growth factor- $\beta 2$ produces an excellent pleurodesis in rabbits. Am. J. Respir. Crit. Care Med. 2000, 162, 98-104. [CrossRef] [PubMed]

38. Lee, Y.C.G.; Teixeira, L.R.; Devin, C.J.; Vaz, M.A.; Vargas, F.S.; Thompson, P.J.; Lane, K.B.; Light, R.W. Transforming growth factor- $\beta 2$ induces pleurodesis significantly faster than talc. Am. J. Respir. Crit. Care Med. 2001, 163, 640-644.

39. Kunz, C.R.; Jadus, M.R.; Kukes, G.D.; Kramer, F.; Nguyen, V.N.; Sasse, S.A. Intrapleural injection of transforming growth factor- $\beta$ antibody inhibits pleural fibrosis in empyema. Chest 2004, 126, 1636-1644. [CrossRef]

40. Hooper, C.E.; Elvers, K.T.; Welsh, G.I.; Millar, A.B.; Maskell, N.A. VEGF and sVEGFR-1 in malignant pleural effusions: Association with survival and pleurodesis outcomes. Lung Cancer 2012, 77, 443-449. [CrossRef]

41. Marchi, E.; Vargas, F.S.; Acencio, M.M.; Antonangelo, L.; Genofre, E.H.; Teixeira, L.R. Evidence that mesothelial cells regulate the acute inflammatory response in talc pleurodesis. Eur. Respir. J. 2006, 28, 929-932. [CrossRef] [PubMed]

42. Najmunnisa, N.; Mohammed, K.A.; Brown, S.; Su, J.; Sriram, P.S.; Moudgil, B.; Loddenkemper, R.; Antony, V.B. Talc mediates angiostasis in malignant pleural effusions via endostatin induction. Eur. Respir. J. 2007, 29, 761-769. [CrossRef] [PubMed]

43. Giuliani, F.; Hader, W.; Yong, V.W. Minocycline attenuates T cell and microglia activity to impair cytokine production in T cell-microglia interaction. J. Leukoc. Biol. 2005, 78, 135-143. [CrossRef] [PubMed]

44. Nasreen, N.; Mohammed, K.A.; Dowling, P.A.; Ward, M.J.; Galffy, G.; Antony, V.B. Talc induces apoptosis in human malignant mesothelioma cells in vitro. Am. J. Respir. Crit. Care Med. 2000, 161, 595-600. [CrossRef] [PubMed]

45. Lee, E.B.; Kim, A.; Kang, K.; Kim, H.; Lim, J.S. NDRG2-mediated modulation of SOCS3 and STAT3 activity inhibits IL-10 production. Immune Netw. 2010, 10, 219-229. [CrossRef]

46. Barroso-Sousa, R.; Ott, P.A. Transformation of old concepts for a new era of cancer immunotherapy: Cytokine therapy and cancer vaccines as combination partners of PD1/PD-L1 inhibitors. Curr. Oncol. Rep. 2018, 20, 1. [CrossRef]

47. Ost, D.E.; Niu, J.; Zhao, H.; Grosu, H.B.; Giordano, S.H. Quality gaps and comparative effectiveness of management strategies for recurrent malignant pleural effusions. Chest 2018, 153, 438-452. [CrossRef]

Publisher's Note: MDPI stays neutral with regard to jurisdictional claims in published maps and institutional affiliations.

(C) 2020 by the authors. Licensee MDPI, Basel, Switzerland. This article is an open access article distributed under the terms and conditions of the Creative Commons Attribution (CC BY) license (http://creativecommons.org/licenses/by/4.0/). 